\title{
Quantitation of norovirus-specific lgG before and after infection in immunocompromised patients
}

\author{
Suliman Qadir Afridi ${ }^{1}$ • Hassan Moeini ${ }^{1}$ • Behnam Kalali ${ }^{2}$ - Jochen Martin Wettengel ${ }^{1}$. Oliver Quitt ${ }^{1}$. \\ Raphaela Semper ${ }^{2} \cdot$ Markus Gerhard $^{2} \cdot$ Ulrike Protzer $^{1} \cdot$ Dieter Hoffmann $^{1}$ (D)
}

Received: 29 May 2019 / Accepted: 12 October 2019 / Published online: 26 October 2019

(C) Sociedade Brasileira de Microbiologia 2019

\begin{abstract}
Noroviruses (NoV) cause the majority of non-bacterial gastroenteritis cases worldwide, with genotype II.4 being the most common. The aim of our study was to quantitate norovirus-specific IgG in immunocompromised patients before and after laboratory-confirmed norovirus infection. A quantitative ELISA was developed by coating ELISA plates with recombinantly expressed P domain of GII.1 capsid protein. After testing mouse sera drawn before and after immunization with GII.1- and GII.4 P domain, sera from GII.1- and GII.4 infected patients were tested. The assay reliably detected preexisting NoV-specific IgG antibodies. Sera drawn after infection showed increased antibody concentrations. Antibodies elicited by GII.1- and GII.4 infections could be detected with coated GII.1 capsid protein. IgG levels remained constant during the first week and then increased in the second week after laboratory diagnosis. The results show that immunocompromised patients elicited IgG responses to NoV infections that could be reliably detected with our quantitative ELISA.
\end{abstract}

Keywords Quantitative ELISA · Human norovirus · $\operatorname{IgG}$ antibody $\cdot$ Capsid protein $\cdot$ P domain

\section{Introduction}

Human NoV cause most of the non-bacterial gastroenteritis cases worldwide [1]. Few viral particles can cause a symptomatic infection [2]. Virions are stable in the environment and are transmitted by contact with infected individuals, through fecal-oral route or exposure to contaminated food and water [3]. NoV is divided into six genogroups, which are further subdivided into at least 30 genotypes. Genogroups GI, GII, and GIV are known to cause infections in humans [4]. GII.4 has been the most prevalent genotype for over a decade, in the last years recombinant genotypes emerged, such as the GII.1 we observed in a hospital out-

Responsible Editor: Flavio Guimaraes Fonseca.

Dieter Hoffmann

dieter.hoffmann@tum.de

1 Institute of Virology, Technische Universität und Helmholtz Zentrum München, Munich, Germany

2 Institute of Medical Microbiology, Immunology and Hygiene, Technische Universität München, Munich, Germany break [5]. The genome contains three open reading frames (ORFs). The ORF1 encode for six non-structural proteins [6]. The viral capsid protein 1 (VP1) and protein 2 (VP2) are encoded by the ORF 2 and 3, respectively [7]. The capsid protein consists of $\mathrm{S}$ (surface) and $\mathrm{P}$ (protruding) domain linked together by a hinge of eight amino acids. The $\mathrm{P}$ domain is further divided into $\mathrm{P} 1$ and P2 [7]. The P2 domain forms the virion's surface and contains most predicted B-cell epitopes and histo-blood group antigen binding sites [8-10].

NoV infections typically elicit only incomplete and temporary immunity. The prevalence of NoV-specific antibodies increase rapidly before the age of 5 years, when most children have been exposed to NoV $[11,12]$. It has been shown that high NoV-specific serum antibody levels correlate with protection from infection $[11,13]$. Increased IgG, IgA, and IgM antibodies have been reliably measured after NoV infections in humans [14-18]. As IgG antibodies are present in higher concentrations in sera than $\operatorname{IgA}$ and $\operatorname{IgM}[19,20]$, we established a quantitative ELISA for serum IgG. Thus we expect to reliably detect preexisting antibodies. We aimed at characterizing humoral immune response in immunosuppressed patients. To this end, we quantitated $\mathrm{NoV}$-specific 
IgG in sequential samples drawn before and after infection. We plan to use these data for monitoring antibody responses in sequential sera from chronically infected patients.

\section{Material and methods}

\section{Patient samples}

Sera originated from immunocompromised patients at "Klinikum rechts der Isar, TUM". We selected patients from whom sera drawn before NoV PCR-confirmed positive stool samples and sera drawn after infection were available. We had samples from these patients drawn before infections stored as residual diagnostic material. They had been sent to our Clinical Virology lab for other diagnostic tests. The local IRB committee "Ethikkommission der Technischen Universität München" approved using residual diagnostic material for study purposes. Ten patients (36 to 89 years of age) met these criteria: 7 had received a kidney transplantation, and 3 were immunosuppressed because of other conditions (e.g., acute leukemia and diabetes). Seven contracted GII.1 infections during an outbreak [5], and three were sporadic GII.4positive cases. All patients had developed clinical gastroenteritis, leading to NoV diagnostic testing.

\section{Cloning, expression, and characterization of recombinant $P$ domain protein}

Recombinant GII.1- and GII.4 capsid P domains were expressed in E. coli. To this end, total nucleic acid was extracted from GII.1 and GII.4 positive stool samples, respectively. RNA was reverse transcribed at $45^{\circ} \mathrm{C}$ for 45 min using SuperScript III (Invitrogen, USA). The complete GII.1 P domain was amplified with Phusion High-Fidelity one-step PCR kit (New England Biolab, Germany) and specific primers 5'GATCGAATTCCGCC CCTCTCCAGATTTTGAT and 5'GATCGCGGCCGCAAAG CTCCAGCCATTACTGC. We amplified the GII.4 P domain with 5'GGATCCATGAAGATGGCGTCGAATGAC and 5' GAATTCTTATAATGCACGTCTACGCCCCGCTCCA. Underlined are restriction sites for cloning. PCR was run in a gradient thermal cycler (Biometra, Germany). Following an initial denaturation step at $95^{\circ} \mathrm{C}$ for $5 \mathrm{~min}, 35$ amplification cycles were run: denaturation at $98{ }^{\circ} \mathrm{C}$ for $10 \mathrm{~s}$, annealing at $63{ }^{\circ} \mathrm{C}$ for $30 \mathrm{~s}$, extension at $72{ }^{\circ} \mathrm{C}$ for $40 \mathrm{~s}$, and a final extension at $72{ }^{\circ} \mathrm{C}$ for $10 \mathrm{~min}$. The amplified fragment of the capsid gene was inserted into the EcoRI and NotI sites of pGEX-4t expression vector (GE healthcare, Germany). The identity of the inserts was confirmed with DNA sequencing. After expression in E. coli BL21, the protein was purified using GST Tag FF column (GE Healthcare, Germany) and then visualized by SDS PAGE and western blotting using rabbit GII.10 polyclonal antibody (provided by Grant Hansman and Anna Koromyslova, DKFZ,
Heidelberg) as primary antibody and horse radish peroxidase (HRP)-conjugated protein A (Thermo Scientific, Germany). Protein A-HRP binds almost exclusively to the intact IgG molecule [21]. Proteins were separated on 10\% SDS-PAGE and then transferred on a methanol-activated PVDF membrane (Sigma Aldrich, Darmstadt, Germany) at $200 \mathrm{~mA}$ for $2 \mathrm{~h}$. Followed by blocking with $5 \%$ milk powder in TBST (Tris-buffered saline, $0.1 \%$ Tween 20 ) for $1 \mathrm{~h}$, the membrane was incubated with rabbit GII.10 polyclonal antibody in TBST $+5 \%$ milk powder at $4{ }^{\circ} \mathrm{C}$ overnight. After washing $(\times 3)$ with TBST buffer, the membrane was incubated with HRP-conjugated protein A $(1 \mu \mathrm{g}$ in TBST+ $5 \%$ milk powder) for $1 \mathrm{~h}$ at RT. Finally, the membrane was washed $(\times 3)$, treated with ECL substrates and then visualized by the Fusion chemiluminescence detector Fx7 (INTAS, Germany).

\section{Mouse immunization}

Four female BALB/c mice were injected intraperitoneally three times with $10 \mu \mathrm{g}$ C-di-AMP (as adjuvant) as well as $30 \mu \mathrm{g}$ GSTfused GII.4- (2 mice) and GII.1, P domain (2 mice) with oneweek intervals (Fig. 1b). Sera were collected 1 week before the first and seventh week after the last immunization. Mouse sera were also tested for ELISA validation. All the procedures were conducted according to protocols approved by legal issues health, consumer protection and pharmacy, Government of Upper Bavaria (ROB-55.2-2532.Vet_02-18-77).

\section{Testing human serum samples with ELISA}

ELISA plates (Nunc Maxisorp, Thermo Scientific, Germany) were coated with $1 \mu \mathrm{g}$ recombinantly expressed $\mathrm{P}$ domain per well for $2 \mathrm{~h}$ at RT. On each plate, a standard curve for quantitating $\operatorname{IgG}$ was generated with serial dilutions of human $\operatorname{IgG}$ in $1 \times$ phosphate-buffered saline (PBS). To this end, wells were coated with $1: 2 \mathrm{IgG}$ dilutions starting from $1 \mu \mathrm{g} / \mathrm{ml}$ to $31.25 \mathrm{ng} / \mathrm{ml}$.

Wells coated with $\mathrm{P}$ domain and $\mathrm{IgG}$ antibodies were washed 3 times with $1 \times$ PBS containing $0.05 \%$ Tween 20 and then

Fig. 1 a SDS PAGE and western blot analysis of GST-tagged GII.1- and GII.4 P domain; the purified proteins were visualized by SDS-PAGE (SP) and western blotting (WB). b Immunization scheme in mice: BALB/c mice were injected three times with GII.1- and GII.4 P domain and C-diAMP. Serum samples drawn 7 days before the first and 49 days after the last immunization were tested. c Quantitative ELISA results of mouse samples: high capsid-specific IgG levels were measured after immunization with GII.1 and GII.4 capsid proteins. d NoV-specific IgG concentrations in immunocompromised patient. Serum samples drawn before and after detecting GII.g/GII.1 and GII.4 infections by PCR were tested. Antibody concentrations remained in the same range for samples drawn in the first 8 days (patients 1 and 2), while they increased thereafter (patients 5, 6, 7, 9, and 10). Mouse GII polyclonal antibody was used as positive control. Negative control: goat serum. Error bars indicate standard deviation 
a

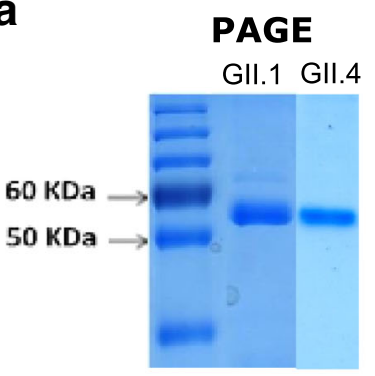

WB

GII.1 GII.4

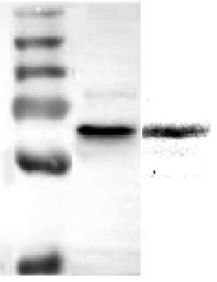

b

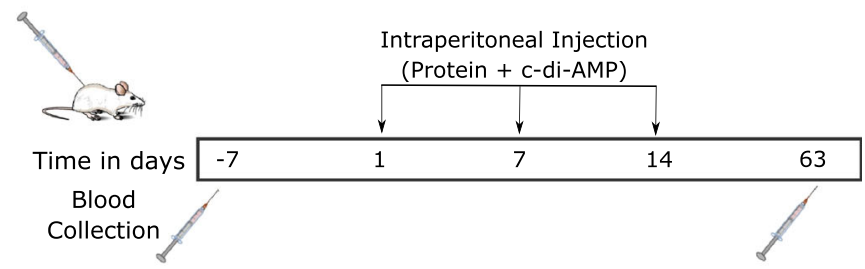

C
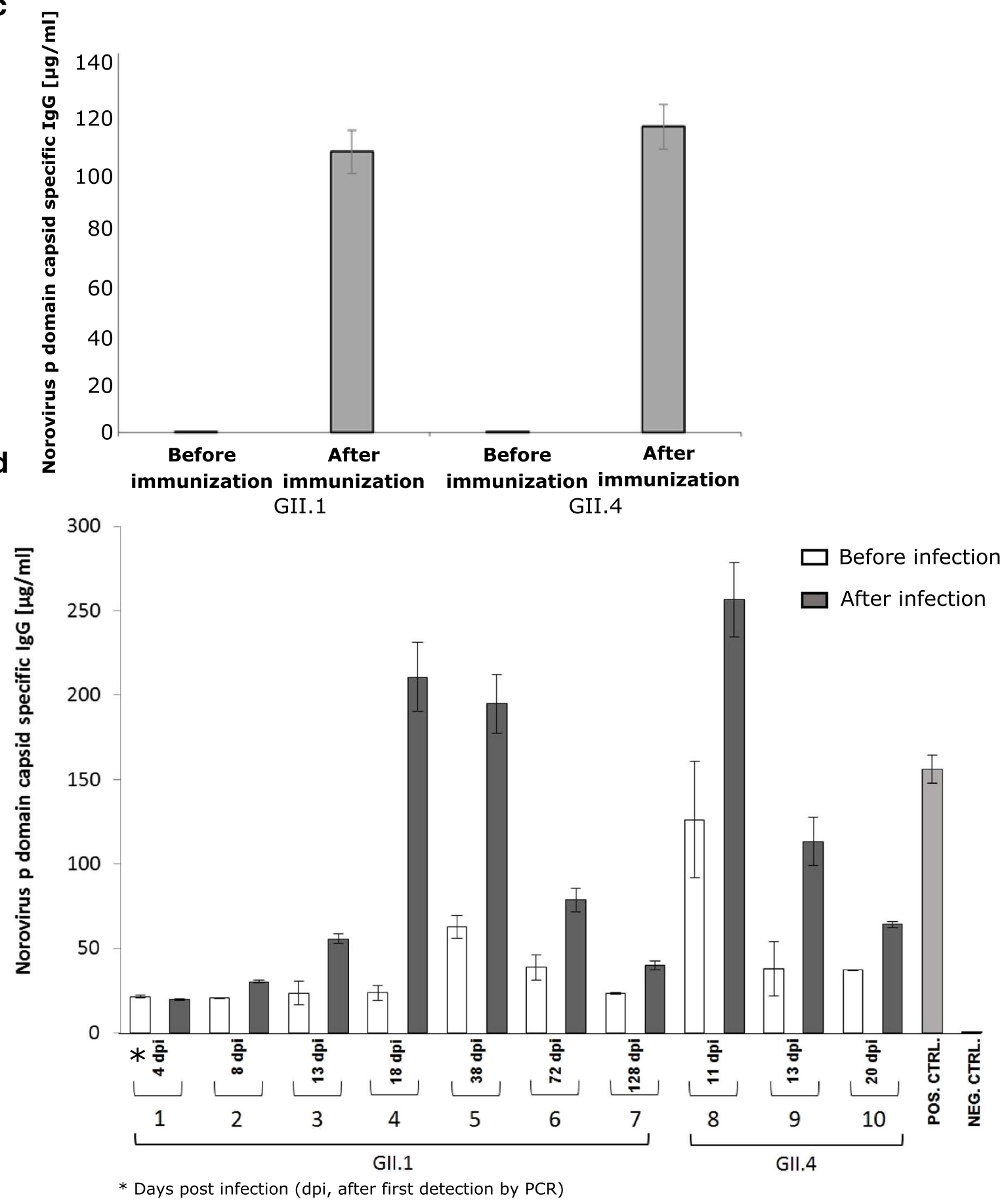
Table 1 Mean, standard deviation, coefficient of variation and $Z$ ' factor of $\mathrm{P}$ domain-specific IgG measured in 9 replicates of mouse sera drawn before (negative) and after (positive) immunization with recombinantly expressed $\mathrm{P}$ domain

\begin{tabular}{llllll}
\hline & \multirow{2}{*}{ GII.1 } & & & \multicolumn{2}{l}{ GII.4 } \\
\cline { 2 - 3 } \cline { 5 - 6 } & Negative & Positive & & Negative & Positive \\
\hline Mean & 0.069 & 1.151 & & 0.098 & 1.116 \\
SD $^{*}$ & 0.006 & 0.111 & & 0.009 & 0.097 \\
CV $^{* *}$ & 0.073 & 0.083 & & 0.089 & 0.078 \\
Z Factor & 0.916 & & & 0.922 & \\
\hline
\end{tabular}

*Standard deviation $* *$ Coefficient of variation

blocked with $250 \mu \mathrm{l} 5 \%$ bovine serum albumin (BSA) for $2 \mathrm{~h}$ at RT followed by 3 times washing. Patient sera were 1:1000 diluted in PBS and $100 \mu \mathrm{l}$ were added to the coated wells. After $1 \mathrm{~h}$ incubation at RT and washing $(5 \times), 100 \mu$ of 1:40,000 protein A diluted in PBS was applied followed by 1 incubation at RT. After washing $(5 \times), 100 \mu \mathrm{l}$ of TMB dye (Sigma Aldrich, Germany) were added to each well, and after 5 to $10 \mathrm{~min}$ incubation at RT, the reaction was stopped with $0.16 \mathrm{M} \mathrm{H}_{2} \mathrm{SO}_{4}$. Absorbance values were measured at $450 \mathrm{~nm}$ on an Infinite F200 ELISA reader (Tecan, Germany).

To show the ELISA is able to detect antibodies directed at $\mathrm{P}$ domain of the capsid protein, serum samples from wild-type mice immunized with NoV P domain were tested. Intra-assay coefficients of variation $(\mathrm{CV})$ and $\mathrm{Z}$ factors were determined as previously described [22]. $\mathrm{CV} \leq 20 \%$ and $\mathrm{Z}^{\prime} \geq 0.4$ were considered acceptance criteria. Each plate included three negative controls: without coating, without primary antibody, and without protein A. Mouse GII polyclonal antibodies served as positive control.

\section{Results and discussion}

Correct expression of GII.1 and GII.4 P2 domains as $57 \mathrm{kDa}$ fusion proteins was confirmed in Western blot (Fig. 1a). Mouse sera, drawn before and after immunization with GII.1 and GII.4 P domain proteins, were tested as initial negative and positive samples. Sera drawn before immunization yielded undetectable signals. High signals were detected in samples drawn after immunization with GII.1 and GII.4 P domain (Fig. 1c). CV and Z' factor (Table 1) confirmed that our ELISA can reliably distinguish between samples before and after vaccination.

In the next step, human serum samples drawn before and after PCR-documented NoV infection were tested. The assay successfully detected capsid-specific IgG in both GII.1- (1-7) and GII.4- (8-10) infected patients (Fig. 1d). Antibodies elicited by GII.4 infections were reliably detected using GII.1 P domain indicating cross reactivity between the antibodies.
Similar IgG concentrations were detected in serum samples drawn before GII.1- (1-7) and GII.4-infections (8-10). NoV antibodies preexisted in all immunocompromised patients. Even high preexisting antibody concentrations as in patient 5 and 8 could not protect against subsequent NoV infection. Previous studies also show no protection by preexisting IgG [23]. It is established that antibodies blocking capsid protein binding to blood group antigens correlate with protection [24]. To specifically measure these antibodies, we plan to establish blocking assays $[25,26]$.

As expected antibody levels remained the same in a sample drawn 4 days after first positive PCR (Fig. 1d, patient 1), no NoV specific IgG had been produced at that time. After 8 days NoV specific IgG slightly increased (patient 2). Antibody concentrations were highest in samples drawn between 13 and 38 days post-infection (patient $4,5,8$, and 9) with the exception of patients 3 and 10 (acute leukemia). In samples drawn at later time points antibody concentrations were lower (patients 6 and 7) which reflects the expected kinetics of B cell responses to viral infections. The antibody increase varies strongly between our 10 patients since the degree of immune suppression differs between them. As we measured similar preexisting antibody concentrations and antibody increases after GII.1 and GII.4 infections we expect to detect antibodies to other GII genotypes as well. Along this line, cross reactive antibodies between NoV genotypes have been described [18].

Our ELISA reliably quantitates NoV capsid antibodies present before infection and antibody increase elicited by PCR-documented GII.4- and GII.1 infection. To our knowledge, this is the first study about NoV specific IgG in immunocompromised persons. Depending on available samples, we plan to extend our study to other GII genotypes and to monitor NoV-specific IgG concentrations in mice immunized with vaccine candidates.

Acknowledgments We thank technicians of the Laboratory of Clinical Virology, TUM for extracting stool samples. Grant Hansman and Anna Koromyslova, DKFZ, Heidelberg provided polyclonal antibodies.

Authors' contribution SQA conducted analyses and experiments and wrote the manuscript. DH designed the project and wrote the manuscript. HM helped analyze data and write manuscript. BK, OQ, RS, and MG assisted in ELISA development. JMW helped clone the capsid gene. UP aided in designing the study and provided resources. All authors read and approved the manuscript.

\section{Compliance with ethical standards}

Ethics approval and consent to participate Not applicable, human samples were residual diagnostic material.

Competing interests The authors declare that they have no conflict of interest. 


\section{References}

1. Atmar RL, Estes MK (2006) The epidemiologic and clinical importance of norovirus infection. Gastroenterol Clin 35(2):275-290

2. Lindesmith L, Moe C, Marionneau S, Ruvoen N, Jiang X, Lindblad L, Stewart P, LePendu J, Baric R (2003) Human susceptibility and resistance to Norwalk virus infection. Nat Med 9(5):548-553

3. Wikswo ME, Hall AJ (2012) Outbreaks of acute gastroenteritis transmitted by person-to-person contact-United States, 20092010. Morbidity and Mortality Weekly Report: Surveillance Summaries 61(9):1-12

4. Vinjé J (2015) Advances in laboratory methods for detection and typing of norovirus. J Clin Microbiol 53(2):373-381

5. Hoffmann D, Mauroy A, Seebach J, Simon V, Wantia N, Protzer U (2013) New norovirus classified as a recombinant GII. g/GII. 1 causes an extended foodborne outbreak at a university hospital in Munich. J Clin Virol 58(1):24-30

6. Subba-Reddy CV, Goodfellow I, Kao CC (2011) VPg-primed RNA synthesis by norovirus RNA-dependent RNA polymerases using a novel cell-based assay. Journal of virology: JVI:06191-06111

7. Thorne LG, Goodfellow IG (2014) Norovirus gene expression and replication. J Gen Virol 95(2):278-291

8. Zakikhany K, Allen DJ, Brown D, Iturriza-Gómara M (2012) Molecular evolution of GII-4 Norovirus strains. PLoS One 7(7): e41625

9. Allen DJ, Gray JJ, Gallimore CI, Xerry J, Iturriza-Gómara M (2008) Analysis of amino acid variation in the P2 domain of the GII-4 norovirus VP1 protein reveals putative variant-specific epitopes. PLoS One 3(1):e1485

10. Lindesmith LC, Ferris MT, Mullan CW, Ferreira J, Debbink K, Swanstrom J, Richardson C, Goodwin RR, Baehner F, Mendelman PM (2015) Broad blockade antibody responses in human volunteers after immunization with a multivalent norovirus VLP candidate vaccine: immunological analyses from a phase I clinical trial. PLoS Med 12(3):e1001807

11. Nurminen K, Blazevic V, Huhti L, Räsänen S, Koho T, Hytönen VP, Vesikari T (2011) Prevalence of norovirus GII-4 antibodies in Finnish children. J Med Virol 83(3):525-531

12. Matsui SM, Greenberg HB (2000) Immunity to calicivirus infection. The Journal of infectious diseases 181(Supplement_2):S331S 335

13. Nakata S, Chiba S, Terashima H, Yokoyama T, Nakao T (1985) Humoral immunity in infants with gastroenteritis caused by human calicivirus. J Infect Dis 152(2):274-279

14. Cukor G, Nowak NA, Blacklow NR (1982) Immunoglobulin M responses to the Norwalk virus of gastroenteritis. Infect Immun 37(2):463-468
15. Iritani N, Seto T, Hattori H, Natori K, Takeda N, Kubo H, Yamano T, Ayata M, Ogura H, Seto Y (2007) Humoral immune responses against norovirus infections of children. J Med Virol 79(8):11871193

16. Lindesmith LC, Donaldson E, Leon J, Moe CL, Frelinger JA, Johnston RE, Weber DJ, Baric RS (2010) Heterotypic humoral and cellular immune responses following Norwalk virus infection. J Virol 84(4):1800-1815

17. Ramani S, Neill FH, Opekun AR, Gilger MA, Graham DY, Estes MK, Atmar RL (2015) Mucosal and cellular immune responses to Norwalk virus. J Infect Dis 212(3):397-405

18. Rockx B, Baric RS, De Grijs I, Duizer E, Koopmans MP (2005) Characterization of the homo-and heterotypic immune responses after natural norovirus infection. J Med Virol 77(3):439-446

19. Irani V, Guy AJ, Andrew D, Beeson JG, Ramsland PA, Richards JS (2015) Molecular properties of human IgG subclasses and their implications for designing therapeutic monoclonal antibodies against infectious diseases. Mol Immunol 67(2):171-182

20. Kavanagh O, Estes MK, Reeck A, Raju RM, Opekun AR, Gilger MA, Graham DY, Atmar RL (2011) Serological responses to experimental Norwalk virus infection measured using a quantitative duplex time-resolved fluorescence immunoassay. Clinical and Vaccine Immunology:CVI:00039-00011

21. Lal A, Haynes SR, Gorospe M (2005) Clean western blot signals from immunoprecipitated samples. Mol Cell Probes 19(6):385-388

22. Iversen PW, Beck B, Chen Y-F, Dere W, Devanarayan V, Eastwood BJ, Farmen MW, Iturria SJ, Montrose C, Moore RA (2012) HTS assay validation. In: Assay Guidance Manual. Eli Lilly \& Company and the National Center for Advancing Translational Sciences

23. Johnson PC, Mathewson JJ, DuPont HL, Greenberg HB (1990) Multiple-challenge study of host susceptibility to Norwalk gastroenteritis in US adults. J Infect Dis 161(1):18-21

24. Atmar RL, Bernstein DI, Lyon GM, Treanor JJ, Al-Ibrahim MS, Graham DY, Vinjé J, Jiang X, Gregoricus N, Frenck RW (2015) Serological correlates of protection against a GII. 4 norovirus. Clinical and Vaccine Immunology:CVI:00196-00115

25. Tamminen K, Huhti L, Koho T, Lappalainen S, Hytönen VP, Vesikari T, Blazevic V (2012) A comparison of immunogenicity of norovirus GII-4 virus-like particles and P-particles. Immunology 135(1):89-99

26. Malm M, Uusi-Kerttula H, Vesikari T, Blazevic V (2014) High serum levels of norovirus genotype-specific blocking antibodies correlate with protection from infection in children. J Infect Dis 210(11):1755-1762

Publisher's note Springer Nature remains neutral with regard to jurisdictional claims in published maps and institutional affiliations. 